\title{
Android-Based Voice Dictionary Application Design as BIPA Learning Media
}

\author{
Tri Wahyono ${ }^{1}$, Budi Agung Sudarmanto ${ }^{2}$, Ida Yeni Rahmawati ${ }^{3}$, and Fitroh Anugrah \\ Kusuma Yudha ${ }^{4}$ \\ ${ }^{1,4}$ Universitas Muhammadiyah Yogyakarta, Indonesia \\ ${ }^{2}$ Balai Bahasa Sumatera Selatan, Indonesia \\ ${ }^{3}$ Universitas Muhammadiyah Ponorogo, Indonesia \\ 1triwahyono@umy.ac.id, 2budi.agung@kemendikbud.go.id, \\ 3idayenir@umpo.ac.id, ${ }^{4}$ fitroh.anugrah.2010@ft.umy.ac.id
}

\begin{abstract}
Skills in speaking foreign languages require not fast process of practice because in learning foreign languages there are differences in the pronunciation of letters, numbers, and words with the first language. A person's speaking skills are strongly influenced by his ability to listen to speech sounds. This study aims to develop a sound dictionary application which is equipped by a search bar facility to provide ease of learning to practice speaking skills for foreign speakers. The process of designing a voice dictionary application using the APP inventor program 2. The process was conducted by inputting the material of letters, numbers, and words in the Indonesian language which is accompanied by the speech sound into the inventor program 2. Material data that has been inputted into an android-based application can be accessed with offline mobile phones. The data were obtained from primary data sourced from KBBI and secondary cubes from the observation of foreign speakers and the process of designing a voice dictionary application according to user requirements. In addition, the data were also taken from the process of testing the developed media done by the participants to find out the evaluation of the development of the voice dictionary application.
\end{abstract}

Keywords: Design, Application, Voice Dictionary, Android-Based

\section{PENDAHULUAN}

Keterampilan berbicara merupakan keterampilan berbahasa yang harus segera dikuasai oleh pembelajar asing. Penutur asing yang mulai belajar berbicara bahasa Indonesia terkadang masih mengalami kesulitan karena perbedaan pengucapan kata, huruf, dan angka. Kemampuan berbicara seseorang sangat dipengaruhi oleh kemampuanya dalam menyimak atau mendengarkan bunyi ujaran. Semakin sering dan semakin banyak seseorang mendengarkan bunyi ujaran bahasa lain, proses belajar berbicara akan semakin cepat. Akan tetapi, proses belajar berbicara harus diimbangi dengan media berlatih pengucapan yang mendukung.

Berdasarkan data dari Pusat Pengembangan Strategi dan Diplomasi Kebahasaan ada sekitar 232 lembaga penyelenggara BIPA di seluruh dunia yang terdapat pada sekitar 45 
negara. BIPA adalah program pembelajaran keterampilan berbahasa Indonesia bagi penutur asing, meliputi berbicara, menulis, membaca, dan mendengarkan [1]. Berkaitan dengan kondisi tersebut, metode yang diterapkan dalam pembelajaran bahasa Indonesia bagi penutur asing harus semakin inovatif agar dapat memudahkan siswa asing dalam belajar bahasa Indonesia.

Media pembelajaran dibutuhkan oleh siswa asing dalam belajar berbicara untuk memberikan kemudahan dalam proses belajar sehingga dapat mendukung keterampilan berbicara pembelajar. Pengembangan media pembelajaran yang akan digunakan oleh peserta didik harus didasarkan pada beberapa pertimbangan, seperti a) dapat menjadi media belajar mandiri baik di dalam maupun di luar sekolah dan b) media pembelajaran dapat digunakan oleh pendidik dalam proses belajar mengajar [2]. Berbicara merupakan salah satu keterampilan berbahasa yang dimiliki oleh setiap orang. Dalam kenyataannya, tidak semua keterampilan tersebut diperoleh di dalam kelas, tetapi juga di luar kelas [3].

Akhir-akhir ini, metode pembelajaran yang sedang trend digunakan adalah memanfaatkan teknologi informasi. Dampak penggunaan perangkat TI dalam bidang pendidikan yaitu terjadinya transformasi dari pembelajaran konvensional menjadi pembelajaran berbasis TI yang disebut dengan electronic learning dan mobile learning. Kehadiran mobile learning ini ditujukan sebagai pelengkap fasilitas pembelajaran dan memberikan kesempatan kepada siswa untuk mempelajari kembali materi yang sudah disampaikan, tetapi kurang dikuasai. Pemanfaatan mobile learning juga mudah digunakan dan dapat diakses di manapun dan kapanpun. Hal ini tentu dapat memberikan pengalaman yang berbeda dalam proses pembelajaran bagi siswa [4].

Penggunaan mobile learning dalam pembelajaran diharapkan dapat meningkatkan keterampilan siswa asing dalam berbicara bahasa Indonesia karena media tersebut mudah digunakan. Mobile learning (m-learning) mempunyai keunggulan antara lain biaya penggunaan murah, mampu mendukung konten materi multimedia, dapat digunakan di berbagai tempat, dan dapat mengurangi biaya pembelajaran. Selain itu, perangkat mobile learning juga lebih ringan jika dibandingkan dengan buku, laptop, atau perangkat komputer lain. Akan tetapi, m-learning juga memiliki beberapa kelemahan seperti daya tahan baterai, ukuran layar, keterbatasan dukungan format dan keterbatasan memori penyimpanan data [5].

Pemanfaatan teknologi informasi dalam aktivitas pembelajaran dapat memudahkan siswa dalam menerima dan mengakses materi pembelajaran sehingga diharapkan dapat meningkatkan pemahaman dan keterampilan siswa terhadap materi yang disampaikan. ELearning atau m-learning merupakan suatu kegiatan belajar yang memungkinkan bahan ajar dapat disampaikan kepada siswa melalui media internet, intranet, atau media jaringan komputer dan perangkat lunak lain [6]. Salah satu alternatif yang dapat mendukung proses belajar berbicara bahasa Indonesia penutur asing adalah dengan media aplikasi kamus suara berbasis android yang dilengkapi search bar (kolom pencari).

Android merupakan sistem operasi berbasis Linux pada telepon seluler. Android menyediakan sistem yang terbuka untuk menciptakan aplikasi sehingga dapat dimanfaatkan menjadi berbagai macam program atau aplikasi yang mudah diakses [7]. Dengan menggunakan smartphone yang terintegrasi sistem android, aplikasi kamus suara dapat diakses dengan mudah sehingga dapat mengenal bentuk ujaran atau suara penyebutan kata dan angka dalam bahasa Indonesia [8]. Media aplikasi kamus suara yang dilengkapi search bar (kolom pencari) dapat digunakan untuk mendengarkan secara langsung bunyi ujaran suatu huruf, angka, dan kata. 


\section{METODE PENELITIAN}

Penelitian ini adalah penelitian terapan dengan menggunakan perangkat lunak (software) untuk membuat aplikasi kamus suara yang dilengkapi search bar (kolom pencari) berbasis android untuk meningkatkan keterampilan berbicara bagi penutur asing. Proses perancangan dilakukan dengan menginput materi jenis huruf, angka, dan kata dalam bahasa Indonesia dari sumber kamus besar bahasa Indonesia (KBBI) yang dilengkapi dengan suara bunyi ujaran yang diambil dari suara robot. Media aplikasi kamus suara tersebut dikembangkan dalam bentuk aplikasi berbasis android sehingga dapat diakses dari telepon genggam secara offline.

Teknik pengumpulan data dilakukan dengan menginput jenis angka dan kata bahasa Indonesia ke dalam aplikasi kamus suara berbasis android. Android standart development kit (SDK) menyediakan perangkat dan application programming interface (API) untuk mengembangkan aplikasi pada sistem android menggunakan bahasa pemrograman java. Android dikembangkan oleh google bernama open handset allience (OHA) yaitu aliansi perangkat selular terbuka yang terdiri dari 47 perusahaan hardware, software, dan perusahaan [9]. Metode yang digunakan dalam perancangan dan pengembangan perangkat lunak media pembelajaran berupa aplikasi kamus suara ini berdasarkan data-data yang tersedia adalah metode deskriptif [10]. Data primer media aplikasi kamus suara diambil dari KBBI yang dimasukkan ke dalam aplikasi dengan dilengkapi bunyi ujarannya. Selain itu, data sekunder diambil dari hasil observasi dan ujicoba terhadap penutur asing yang sedang kuliah di UMY. Berikut langka-langkah pengembangan aplikasi kamus suara yang dilengkapi search bar (kolom pencari) berbasis android.

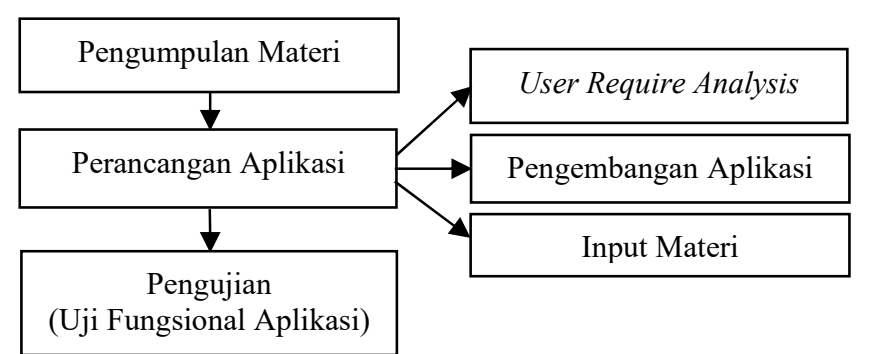

Gambar 1. Tahapan pengembangan aplikasi kamus suara

Proses perancangan aplikasi kamus suara menggunakan program App Inventor 2 (AI2). Program tersebut merupakan Integrated Development Environment (IDE) generasi kedua dari App Inventor yang dikelola oleh Massachusetts Institute of Technology (MIT). AI2 berbasis cloud dapat diakses menggunakan internet browser. Aplikasi tersebut termasuk kategori pemrograman visual dengan menggunakan block puzzle yang disusun untuk menjadi rangkaian kode [11]. Proses perancangan pada tahap ini juga melalui tahapan analisis kebutuhan pengguna (user require analysis, pengembangan aplikasi, dan pengimputan materi.

Aplikasi media pembelajaran tersebut diuji coba pada tahap akhir menggunakan intrumen pendukung penggunaan aplikasi tersebut. Selanjutnya, responden akan memberikan evaluasi sehingga proses pengembangan aplikasi kamus suara yang dilengkapi search bar (kolom pencari) berbasis android dapat diukur kualitasnya. Uji coba perangkat lunak atau aplikasi kamus suara bertujuan memastikan bahwa fungsi pada sistem yang telah dirancang dapat berkerja dan berjalan sesuai harapan [12]. 


\section{HASIL DAN PEMBAHASAN}

Proses pengembangan aplikasi kamus suara menggunakan program APP inventor 2 (AI2). Program (software) tersebut dapat digunakan untuk membuat aplikasi android berupa kamus suara. Program aplikasi untuk menginstal atau merancang aplikasi tersebut dapat diakses/diunggah secara online. Proses penginstalan juga dilakukan secara online menggunakan akun google. Proses perancangan dilakukan dengan menginput kata-kata dan merekam suara/ujaran pelafalannya.

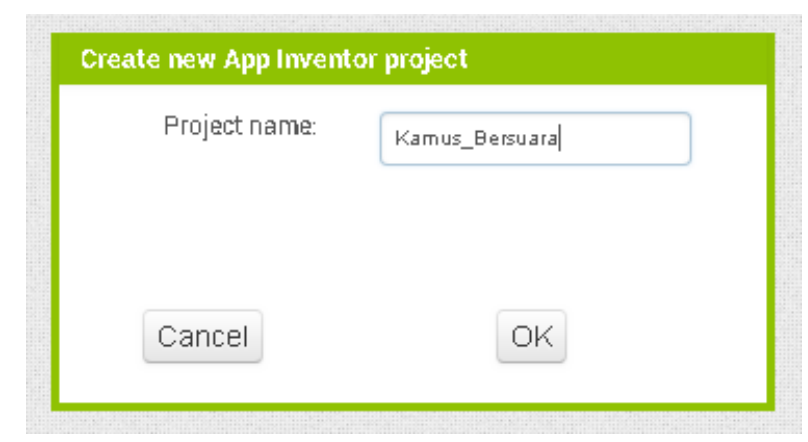

Gambar 2. Tampilan memberi nama project baru

Proses selanjutnya adalah perancangan kamus suara yang dilengkapi dengan kolom pencari (search bar). Pembuatan kolom pencari dilakukan dengan membuat kolom yang diletakkan di bagian tengah pada screen yang tersedia. Setelah pembuatan kolom pencari berhasil, proses berikutnya adalah pembuatan tool untuk dapat memunculkan suara dari kata yang dicari. Selanjutnya, kolom pencari yang telah jadi dihubungkan (di-link-kan) pada input kata dan suara yang telah tersedia dalam sistem aplikasi. Proses menghubungkan ketiga variabel (kata, suara, dan kolom pencari) tersebut dipastikan sesuai dan saling terkait sehingga tidak ada perbedaan antara kata yang diketik pada kolom pencari (search bar) dan bunyi ujaran yang tersedia. Berikut ini (gambar 3) adalah proses pembuatan kolom pencari dan tool pemunculan suara pada halaman kerja pada program APP Inventor 2.

Proses pemrograman antara input kata dan suara pada halaman kerja pada program APP Inventor 2 ditunjukkan pada gambar 4 (a). Setelah data kata diinput pada block kode, data suara juga diinput dengan menyesuaikan antara bunyi suara dan kata yang ditulis. Blok tersebut memberikan gambaran bahwa aplikasi dirancang agar ketika kolom "Bicara" di-klik akan memunculkan suara pelafalan yang sesuai dengan kata yang diketik

Gambar 4 (b) menunjukkan hasil setelah proses pemrograman selesai, project pembuatan aplikasi kamus suara dijadikan dalam bentuk aplikasi (apk) dengan meng-klik (build) dan disimpam pada my computer. Selanjutnya, kirimkan file apk tersebut ke smartphone android pengguna. File apk yang sudah diunggah dapat di-install pada smartphone android pengguna hingga dapat dioperasikan. Berikut (Gambar 5) adalah contoh gambar proses penginstalan yang sudah berhasil dan dapat digunakan untuk mecari bunyi ujaran pada kata yang tersedia. 


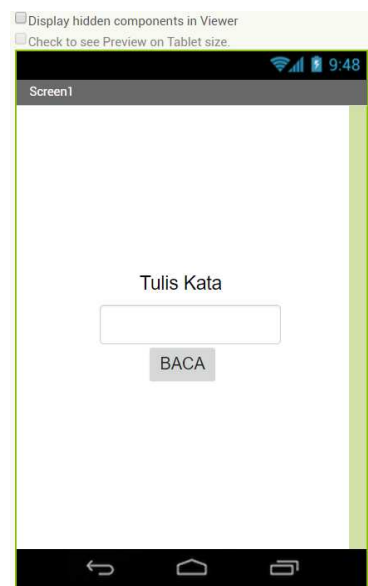

(a)
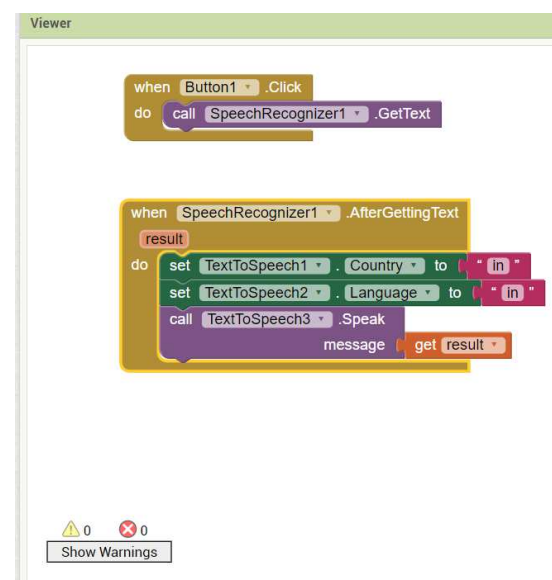

(b)

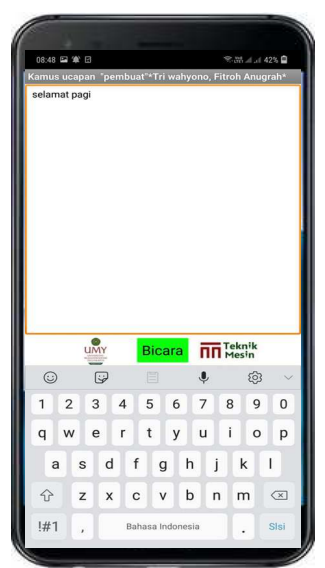

(c)

Gambar 3. Alur perancangan aplikasi: (a) Tampilan desain dari project Kamus Bersuara bahasa Indonesia , (b) Block Code dari aplikasi Kamus Bersuara bahasa Indonesia,

(c) Tampilan Aplikasi Kamus Suara Bahasa Indonesia

Pada gambar 3 (c), ditunjukkan hasil perancangan kamus suara yang sudah mudah diakses dapat digunakan dalam aktivitas pembelajaran berbicara bahasa Indonesia baik di kelas secara reguler atau secara mandiri oleh penutur asing. Penggunaan aplikasi kamus suara ini diharapkan dapat meningkatkan keterampilan penutur asing dalam berbahasa Indonesia secara mandiri. Aplikasi kamus suara yang sudah dirancang dapat diakses secara offline sehingga mudah digunakan di manapun tanpa harus terkoneksi dengan jaringan internet. Jika aplikasi tersebut dibuka, tampilan yang muncul adalah berupa halaman kosong yang dapat diisi dengan tulisan yang dibutuhkan. Selanjutnya, pengguna dapat menekan bagian kolom hijau bertuliskan "Bicara" agar dapat memunculkan bunyi suara atau ujaran berdasarkan kata yang ditulis.

Berbeda dengan hasil rancangan aplikasi media pembelajaran BIPA berbasis android oleh perancang sebelumnya [13] berisi media aplikasi android tentang pengenalan budaya kuliner Indonesia dengan menebak gambar jenis makanan yang tersedia dengan menekan atau mengklik kolom kata jenis-jenis makanan yang sudah tersedia, kemudian pada akhir tampilan akan muncul skor berdasarkan jawaban yang benar. Aplikasi media pembelajaran BIPA berbasis android yang dirancang oleh penulis lebih fokus pada peningkatan keterampilan berbicara dengan menuliskan kata yang dibutuhkan atau diinginkan, kemudian meng-klik kolom bertuliskan "Berbicara" maka akan muncul suara atau ujaran sesuai kata yang ditulis.

Hasil rancangan aplikasi kamus suara yang dibuat penulis juga berbeda dengan rancangan aplikasi android yang dilakukan oleh perancang sebelumnya [14] berisi materi pembelajaran dengan tampilan animasi, tampilan soal interaktif, dan tampilan soal evaluasi. Rancangan aplikasi yang dibuat oleh penulis tidak menampilkan soal evaluasi karena aplikasi ini hanya melatih keterampilan siswa dalam berbicara dengan memunculkan bunyi ujaran dari kata yang ditulis pada kolom dalam aplikasi tersebut. Selain itu, aplikasi ini juga tidak menampilkan materi secara langsung, tetapi materi yang terdapat pada aplikasi ini adalah materi bunyi ujaran yang akan muncul jika pengguna menuliskan kata pada kolom yang tersedia. 
Media pembelajaran aplikasi kamus suara berbasis android yang dirancanag oleh penulis juga berbeda dengan aplikasi media pembelajaran yang dirancang oleh [15]. Media pembelajaran berupa aplikasi berbasis android tersebut dirancang menggunakan sistem atau program Appypie, sedangkan aplikasi kamus suara yang dirancang oleh penulis menggunakan program APP Inventor 2. Sistem ini dapat mendukung proses pembuatan aplikasi pembelajaran berbasis Android, Mac OS, Windows Phone, Blackberry, dan HTML 5. Kelemahan dari pembuatan aplikasi pembelajaran dengan Appypie adalah aplikasi yang sudah dibuat secara gratis ini hanya dapat diperbaiki setelah 24 pembuatan. Selain itu, sistem ini hanya dapat dikerjakan secara online dengan kuota internet yang cukup besar, dan jika sudah di-instal dalam smartphone akan muncul iklan yang dapat mengganggu tampilan aplikasi.

Berdasarkan perbandingan hasil perancangan antara aplikasi yang dirancang oleh penulis dan beberapa rancangan aplikasi media pembelajaran berbasis android yang lain, aplikasi kamus suara berbasis android yang dilengkapi kolom pencari (search bar) memiliki keunggulan berupa kemudahan dalam mengakses dan tidak memunculkan tampilan iklan sehingga dapat menggangu penggunaan aplikasi tersebut. Selain itu, aplikasi ini juga memberikan kesempatan yang sangat luas kepada pengguna untuk menentukan kata yang akan ditulis dan dimunculkan contoh suara pelafalan kata tersebut. Akan tetapi, aplikasi ini juga memiliki kelemahan berupa contoh suara pelafalan kata yang diinginkan diucapkan oleh robot sehingga ketepatan pelafalan kata yang dimunculkan masih kurang.

\section{PENUTUP}

Aplikasi kamus suara yang dilengkapi kolom pencari (search bar) merupakan media pembelajaran berbicara bahasa Indonesia bagi penutur asing yang dapat diakses secara mandiri melalui smartphone dengan sistem android. Pengguna aplikasi kamus suara dapat menginstal aplikasi yang dikirim melalui smartphone. Aplikasi ini dapat dijadikan sebagai media alternatif pembelajaran bahasa Indonesia pada tingkat pemula karena pengguna dapat memanfaatkan aplikasi ini dengan mendengarkan bunyi ujaran kata yang dicari tanpa harus didampingi oleh pengajar atau penutur asli (native speaker). Aplikasi ini juga memberikan kemudahan kepada pengguna untuk menuliskan kata-kata dalam bahasa Indonesia dan memunculkan suara pelafalan kata tersebut [16].

\section{UCAPAN TERIMA KASIH}

Penulis menyampaikan terima kasih kepada Lembaga Penelitian, Publikasi, dan Pengabdian Kepada Masyarakat UMY yang telah memberikan dukungan materi dalam pelaksanaan penelitian tersebut. Selain itu, ucapan terima kasih juga disampaikan kepada mahasiswa asing yang sedang menjalani studi di Universitas Muhammadiyah Yogyakarta karena telah membantu dan mendukung proses perancangan aplikasi kamus suara berbasis android ini. Ucapan terima kasih juga disampaikan kepada segenap dosen dan staff di Program Studi Teknik Mesin, Fakultas Teknik, UMY karena telah memberikan kepercayaan dan dukungan untuk mengerjakan penelitian sehingga mendapatkan hasil berupa aplikasi kamus suara berbasis android yang dilengkapi kolom pencari (search bar). 


\section{REFERENCES}

[1] E. Emilia, "Materi Lokakarya BIPA: "Draft Permendikbud: Standardisasi Program BIPA dalam Rangka Peningkatan Fungsi Bahasa Negara"," in Materi Lokakarya BIPA: "Draft Permendikbud: Standardisasi Program BIPA dalam Rangka Peningkatan Fungsi Bahasa Negara", 2016.

[2] J. Kuswanto and F. Radiansah, "Media Pembelajaran Berbasis Android Pada Mata Pelajaran Sistem Operasi Jaringan Kelas XI,” J. Media Infotama, vol. 14, no. 1, 2018.

[3] A. S. Astriani, "Pengaruh Kebiasaan Menonton Televisi Acara Informasi dan Pergaulan Teman Sebaya terhadap Keterampilan Berbicara Siswa Kelas VIII MTs NU Ungaran," J. Pendidik. Bhs. dan Sastra Indones., vol. 2, no. 2, 2013.

[4] R. julia Purbasari, M. S. Kahfi, and M. Yunus, "Pengembangan Aplikasi Android Sebagai Media Pembelajaran Matematika Pada Materi Dimensi Tiga Untuk Siswa SMA Kelas X," J. Online Univ. Negeri Malang, pp. 1-11, 2013.

[5] S. Yuntoto, "Pengembangan aplikasi android sebagai media pembelajaran kompetensi pengoperasian sistem pengendali elektronik pada siswa kelas XI SMKN 2 Pengasih," Skripsi. Yogyakarta Univ. Negeri Yogyakarta, 2015.

[6] M. Iqbal, Y. Yusrizal, and M. Subianto, "Perancangan Media Pembelajaran Aplikasi Fisikapada Pokok Bahasan Fluida Statis Untuk Siswa SMA Berbasis Android," J. Pendidik. Sains Indones., vol. 4, no. 2, pp. 20-24, 2016.

[7] A. K. Amin and N. Mayasari, "Pengembangan Media Pembelajaran Berbentuk Aplikasi Android Berbasis Weblog Untuk Meningkatkan Hasil Belajar Mahasiswa Pendidikan Matematika Ikip Pgri Bojonegoro," Magistra, vol. 94, no. 27, pp. 12-23, 2015.

[8] R. Wardan and D. Kurniadi, "Aplikasi Multimedia Pembelajaran Rambu Lalu Lintas Berbasis Android," J. Algoritm., vol. 14, no. 2, pp. 1-8, 2017.

[9] S. Wirayudha, "Perancangan Aplikasi Berbasis Android Untuk Aktivitas Manajemen Material Galangan Kapal Baru.” Institut Teknologi Sepuluh Nopember, 2017.

[10] U. Ependi and N. Sopiah, "Pemanfaatan Teknologi Berbasis Android Sebagai Media Belajar Matematika Anak Sekolah Dasar," Matrik, vol. 17, no. 2, pp. 109-122, 2015.

[11] E. S. Wihidayat and D. Maryono, "Pengembangan aplikasi android menggunakan integrated development environment (IDE) App Inventor-2," Edutic-Scientific J. Informatics Educ., vol. 4, no. 1, 2017.

[12] T. Willay, R. J. Iskandar, and A. Haryanto, "Perancangan Aplikasi Penyampaian Informasi Tentang Kampus Dengan Multicast Berbasis Android," INTEKSIS, vol. 1, no. 3, 2014.

[13] I. Y. Rahmawati, "Rancang Bangun Aplikasi Pengenalan Materi Pengajaran Bahasa Indonesia bagi Penutur Asing (BIPA) Berbasis Android di Universitas Muhammadiyah Ponorogo," 2019.

[14] R. S. Putra, N. Wijayati, and F. W. Mahatmanti, "Pengaruh penggunaan media pembelajaran berbasis aplikasi android terhadap hasil belajar siswa," J. Inov. Pendidik. Kim., vol. 11, no. 2, 2017.

[15] I. A. D. Astuti, D. Dasmo, and R. A. Sumarni, "Pengembangan Media Pembelajaran Berbasis Android dengan Menggunakan Aplikasi Appypie di SMK Bina Mandiri Depok," J. Pengabdi. Kpd. Masy., vol. 24, no. 2, pp. 695-701, 2018.

[16] R. Rahim, K. Saddhono, and D. Sulaksono. Unified modeling language as a design of interactive ebook application for android. Journal of Advanced Research in Dynamical and Control Systems. vol. issue. 5 pp. 634-637, 2019 
